\title{
Rezijanščina: geneolingvistična in sociolingvistična opredelitev
}

AвSTRACT: Šekli Matej, Rezijanščina: geneolingvistična in sociolingvistična opredelitev (Resian: Genealogical and Sociolinguistic Definition). „Poznańskie Studia Slawistyczne” 8. Poznań 2015. Publishing House of the Poznan Society for the Advancement of the Arts and Sciences, pp. 199214. ISSN 2084-3011.

The article presents a genealogical and sociolinguistic classification of Slavic idioms, drawing on the example of Resian. Resian is an autochthonous idiom, spoken in the Resia Valley (Ital. Val Resia), which belongs to the Municipality of Resia (Rozajanski kumün, Ital. Comune di Resia) within the Province of Udine (Ital. Provincia di Udine) in Friuli-Venezia Giulia, an autonomous Italian region. The genealogical linguistics studies the genealogical relationship between idioms and on the basis of the nature of their mutual relationship establishes their genealogical classification. In this respect, Resian must be viewed as a dialect of Slovene. Sociolinguistics, on the other hand, tends to view languages as systems of communication and on the basis of different spheres of usage assigns their sociolinguistic classification. From the latter viewpoint, Resian can be defined as a literary/standard microlanguage within Slovene, which due to the absence of the Slovene standard language is put into the role of the local literary language with a rather limited scope of functional varieties.

KEYwords: genealogical classification; sociolinguistic classification; Slavic languages; Slavic literary/standard languages; Slavic literary/standard microlanguages; Resian dialect of Slovene; Rezijansko dialect; Resian literary/standard microlanguage

\section{Jezikoslovne klasifikacije idiomov}

Jezikoslovje (lingvistika) preučuje različne pojavnosti naravnega človeškega jezika ter se glede na zorni kot pogleda nanj deli na tri temeljne veje. To so geneolingvistika (genetsko jezikoslovje), ki preučuje genetska, tj. sorodstvena razmerja med idiomi, tipolingvistika (tipološko jezikoslovje), ki preučuje zgradbo nekega idioma, in sociolingvistika (družbenostno jezikoslovje), ki jezik preučuje kot sporazumevalni sistem kolektiva ali 
posameznika $^{1}$. Te tri temeljne veje jezikoslovja so medsebojno teoretično in metodološko neodvisne, kar pomeni, da spoznanja ene od njih niso prenosljiva na ostali dve. Posledično obstajajo tudi tri medsebojno neodvisne klasifikacije idiomov, in sicer geneo-, tipo- in sociolingvistična. Ker v slavistiki lahko prihaja do mešanja različnih vrst klasifikacij, predvsem geneo- in sociolingvistične, ter pojmov znotraj le-teh, kot sta jezik in knjižni/ standardni jezik, sta v nadaljevanju geneo- in sociolingvistična klasifikacija predstavljeni na primeru slovanskih idiomov.

\subsection{Jezik v geneolingvističnem pomenu}

Jezik v geneolingvističnem pomenu je zemljepisna jezikovna pojavnost (geolekt) in je definiran kot abstraktni (tj. diasistemski) organski (tj. nestandardizirani) idiom višje hierarhične stopnje ${ }^{2}$. Gre torej za množico vseh krajevnih govorov, ki izkazujejo iste jezikovne značilnosti (arhaizme in inovacije), ne pa tudi jezikovnih značilnosti sosednje množice krajevnih govorov, ki posledično tvorijo sosednji ,jezik”. Slovanski jeziki v geneolingvističnem pomenu so (bili): a) južnoslovanski: slovenski, osrednjejužnoslovanski (hr. srednjojužnoslavenski jezik) (ki ga sestavljajo kajkavščina, čakavščina, zahodna in vzhodna štokavščina ter torlaščina), makedonski, bolgarski; b) vzhodnoslovanski: ruski, beloruski, ukrajinski; c) zahodnoslovanski: poljski, pomorjanski (ohranjeno je samo njegovo vzhodno obrobje na vzhodnem Pomorjanskem, tj. kašubščina s slovinščino, izumrlo v drugi polovici 20. stoletja), polabski (izumrl sredi 18. stoletja), lužiški ali lužiškosrbski (ohranjeno je samo njegovo vzhodno obrobje v Dolnji in Gornji Lužici), češki, slovaški ${ }^{3}$. Predstavljeni so na primer v reprezentativnem standardnem delu The Slavonic Languages (Comrie, Corbett 2002), ki prikazuje njihove „krovne” knjižne/standardne jezike in polabščino.

${ }^{1}$ Delitev jezikoslovja na tri temeljne veje je povzeta po Brozović 1996.

${ }^{2}$ Teorija geneolingvistične delitve idiomov na podlagi meril organskost : neorganskost, konkretnost : nekonkretnost (sistemskost, diasistemskost, nesistemskost), višja : nižja hierarhična stopnja je povzeta po Brozović 1970: 10-14.

${ }^{3}$ Geneolingvistična klasifikacija slovanskih idiomov je natančneje predstavljena v Šekli 2013a, 2013b, 2014a, 2014b. 


\subsection{Knjižni/standardni jezik kot sociolingvistični pojem}

Če je ,jezik” geneolingvistični pojem, je sociolingvistični pojem „knjižni/standardni jezik”. Del sociolingvističnega preučevanja so tudi t. i. „knjižni/standardni mikrojeziki”.

Knjižni/standardni jezik ni zemljepisna, temveč družbena jezikovna pojavnost (sociolekt) in je definiran kot konkretni (tj. sistemski) neorganski (tj. standardizirani) idiom najvišje hierarhične stopnje. Posebnost knjižnega/standardnega jezika $\mathrm{v}$ primerjavi z drugimi sociolekti je po teoriji praške jezikoslovne šole predvsem v zanj značilnih specifičnih družbenih vlogah, t. i. narodnopovezovalni in narodnopredstavniški vlogi, iz katerih izhajajo tudi njegove lastnosti, v prvi vrsti njegova široka funkcijskozvrstna razčlenjenost (praktično sporazumevalni, publicistični, strokovni in umetnostni jezik) ${ }^{4}$. Tako se število ,jezikov" kot zemljepisnih jezikovnih pojavnosti pogosto ne ujema s številom njihovih „krovnih” knjižnih jezikov kot družbenih jezikovnih pojavnosti. V okviru slovanskega jezikovnega sveta se na primer srečujemo z več knjižnimi/standardnimi jeziki kot ,jeziki”. Šolski primer predstavlja osrednjejužnoslovanski jezik, na katerega jezikovnem ozemlju so se izoblikovali štirje knjižni/standardni jeziki (hrvaški, srbski, bosenski in črnogorski). Podobno se na ozemlju lužišk[osrbsk]ega jezika pojavljata dva knjižna/standardna jezika (dolnjelužišk[osrbsk]i in gornjelužišk[osrbsk]i). Slovanski knjižni/standardni jeziki so torej slovenski, hrvaški, srbski, bosenski, črnogorski, makedonski, bolgarski, ruski, beloruski, ukrajinski, poljski, kašubski, dolnjelužišk(osrbsk)i, gornjelužišk(osrbsk)i, češki in slovaški knjižni/standardni jezik.

Knjižni/standardni mikrojezik ${ }^{5}$, imenovan tudi pokrajinski ali krajevni knjižni/standardni jezik, je podobno kot knjižni/standardni jezik dru-

\footnotetext{
${ }^{4}$ Praška teorija knjižnega jezika je povzeta po Havránek 1963a, 1963b, 1969.

${ }^{5}$ Pojem rus. литературный микроязык je v slavistiko uvedel Duličenko leta 1981. Njegova obravnava tega pojava se zdi problematična predvsem s teoretičnega vidika, saj knjižni/ standardni mikrojezik definira preprosto kot rus. язык мальх этнических групn, tj. glede na število govorcev, ne pa na primer glede na pravni status idioma, sfer njegove uporabe in njegovih sporazumevalnih funkcij, kar vse so domene sociolingvistike. Tako sta pri Duličenku v publikacijah po letu 1981 na primer gornja lužiška srbščina in rezijanska slovenščina popolnoma izenačeni, čeprav je prva uradno priznana kot uradni jezik v Svobodni deželi Saški (v Nemčiji) in ima razvit polnofunkcionalni knjižni/standardni jezik (ki ni nujno uporabljan v vseh sferah sporazumevanja), ki opravlja narodnopovezovalno in narodnopredstavniško
} 
Tab. Geneolingvistična in sociolingvistična klasifikacija slovanskih idiomov

\begin{tabular}{|c|c|c|}
\hline Geneolingvistična & Sociolir & na klasifikacija \\
\hline slovanski jeziki: & $\begin{array}{l}\text { slovanski knjižni } \\
\text { (makro)jeziki: }\end{array}$ & $\begin{array}{l}\text { slovanski knjižni } \\
\text { mikrojeziki: }\end{array}$ \\
\hline slovenski & slovenski & $\begin{array}{l}\text { rezijanski } \\
\text { beneškoslovenski } \\
\text { porabskoslovenski }\end{array}$ \\
\hline osrednjejužnoslovanski & hrvaški & $\begin{array}{l}\text { gradiščanskohrvaški } \\
\text { moližanskohrvaški }\end{array}$ \\
\hline & $\begin{array}{l}\text { srbski } \\
\text { bosenski } \\
\text { črnogorski }\end{array}$ & $\begin{array}{l}- \\
- \\
-\end{array}$ \\
\hline makedonski & makedonski & - \\
\hline bolgarski & bolgarski & $\begin{array}{l}\text { pomaški } \\
\text { banatskobolgarski }\end{array}$ \\
\hline ruski & ruski & - \\
\hline beloruski & beloruski & - \\
\hline ukrajinski & ukrajinski & $\begin{array}{l}\text { rusinski (z več različicami) } \\
\text { zahodnopoleški }\end{array}$ \\
\hline poljski & poljski & $\begin{array}{l}\text { šlezijski } \\
\text { laški }\end{array}$ \\
\hline pomorjanski & kašubski & - \\
\hline$\dagger$ polabski & - & - \\
\hline lužišk(osrbsk)i & $\begin{array}{l}\text { dolnjelužišk(osrbsk)i } \\
\text { gornjelužišk(osrbsk)i }\end{array}$ & - \\
\hline češki & češki & - \\
\hline slovaški & slovaški & - \\
\hline
\end{tabular}

žbena jezikovna pojavnost (sociolekt) in je definiran kot konkretni (tj. sistemski) neorganski (tj. standardizirani) idiom, ki na nekem zemljepisno omejenem območju znotraj ,,jezika” ali dela ,jezika” opravlja družbe-

vlogo med Lužiškimi Srbi v Gornji Lužici, druga pa nepriznana kot uradni jezik, s funkcijsko zelo omejenim knjižnim/standardnim jezikom, ki ima sporazumevalno vlogo znotraj ozke lokalne skupnosti. 
no sporazumevalno vlogo namesto „krovnega” knjižnega/standardnega jezika oziroma jo opravlja skupaj z njim zaradi odsotnosti ali le delne prisotnosti le-tega. Od „krovnega” knjižnega/standardnega jezika pa se razlikuje predvsem po zmanjšani družbeni vlogi, saj zaradi zemljepisne omejenosti svojega delovanja lahko opravlja kvečjemu pokrajinsko povezovalno in pokrajinsko predstavniško vlogo, kar se zrcali tudi v njegovi okrnjeni funkcijskozvrstni razčlenjenosti. Če lahko „krovni” knjižni/ standardni jezik v idealnem primeru na nek način celo predstavlja ,,jezik" v geneolingvističnem pomenu, lahko pokrajinski knjižni jezik predstavlja kvečjemu narečje ali skupino narečij. S tega stališča se torej zdi izenačevanje pojavnosti knjižnega/standardnega mikrojezika s pojavnostjo „krovnega" knjižnega/standardnega jezika v sociolingvističnem pojmovanju ali celo ,jezika" v geneolingvističnem pomenu, kot se to dogaja na primer $\mathrm{v}$ delih Einführung in die slavischen Sprachen (Rehder 1998) in Lexikon der Sprachen des europäischen Ostens (Okuka 2002), neupravičeno. Slovanski knjižni/standardni mikrojeziki sodobne Slavije so na primer: rezijanski, beneškoslovenski, porabskoslovenski; gradiščanskohrvaški, moližanskohrvaški; pomaški, banatskobolgarski; rusinski, zahodnopoleški; šlezijski, laški 6 .

\section{Rezijanščina geneolingvistično}

Rezijanščina je geneolingvistično definirana kot narečje slovenskega jezika. Po starejših jezikovnih spremembah, ki odražajo diahrono delitev, sodi med severna slovenska narečja, po mlajših jezikovnih pojavih znotraj sinhrone klasifikacije pa se uvršča $\mathrm{v}$ primorsko narečno skupino. V nadaljevanju je rezijanščina na osnovi svojih glasovnih značilnosti umeščena v diasistem slovenskega jezika ${ }^{7}$.

${ }^{6}$ Zgodovinski pokrajinski knjižni jeziki, ki predstavljajo stanje pred poenotenjem nekaterih slovanskih knjižnih jezikov (na primer prekmurskoslovenski, kajkavskohrvaški, čakavskohrvaški, egejskomakedonski, vzhodnoslovaški ipd.) in spadajo v zgodovino posameznih slovanskih knjižnih jezikov, kot tudi (neuspeli) poskusi oblikovanja knjižnih/standardnih mikrojezikov (na primer galšanskobeloruski in vičskopoljski v Litvi) niso upoštevani.

${ }^{7}$ Značilnosti drugih jezikovnih ravnin so za geneolingvistično klasifikacijo manj relevantne. Podobno velja za tujejezične prvine. 
Rezijansko narečje slovenščine se je do 14. stoletja oblikovalo skupaj z ostalimi severnimi, tj. koroškimi slovenskimi narečji. Najbolj sorodno je sosednjemu ziljskemu narečju, ki je zgodovinsko prisotno v Kanalski dolini (it. Val Canale, Italija), spodnji Ziljski dolini (nem. Gailtal, Avstrija) in v okolici Rateč ter Kranjske Gore (Slovenija). Po romanizaciji Železne doline (it. Canal del Ferro) in s posledično izgubo stika z ziljščino se je rezijanščina začela spreminjati skupaj s primorskimi slovenskimi narečji. Rezijansko narečje ozemeljsko meji na vzhodu na obsoško, na jugu pa na tersko narečje slovenščine. Iz teh so se v rezijansko narečje širile nekatere mlajše jezikovne inovacije, zaradi česar se rezijanščina po mlajših jezikovnih spremembah uvršča med narečja primorske narečne skupine.

Na severnoslovenski izvor rezijanščine kažejo predvsem starejše glasovne spremembe. Slovenska $* \bar{e}, * \bar{o}$ sta se v severozahodni slovenščini diftongirala $\mathrm{v} * i e, *^{*} u$ ter se nato $\mathrm{v}$ rezijanskem, cerkljanskem in južnem delu rožanskega narečja monoftongirala $\mathrm{v} \bar{l}, \bar{u}:{ }^{8} \operatorname{sln} . *_{\bar{e}},{ }^{*} \bar{o}>\mathrm{SZ} \operatorname{sln}$. *ie, $*_{u o}>$ rez. sln. $i, u$ : JV sln. *ei, *ou > knj. sln. ẹ, ọ (rez. sln. lis, sinca, bil, w-lizën, dilan, drivë = knj. sln. lệs, sệnca, bẹ́l, lệzem, dệlam, drẹ́vi; rez. sln. nus, kust, pet utruk, bus, stu, an jë stupil sul = knj. sln. nộs, kộst, pẹ́t otrọ́k, bộs, stộ, ön je stộpil sộl). V severni in vzhodni slovenščini se je slovenski ${ }^{*} \bar{\partial}$ vokaliziral $\mathrm{v}{ }^{*} \bar{e}: \operatorname{sln} .{ }^{*} \bar{\partial}>\mathrm{S}$ in $\mathrm{V} \operatorname{sln} .{ }^{*} \bar{e}>$ rez. $\operatorname{sln} . e: \mathrm{Z}$ in $\mathrm{J} \operatorname{sln} . * \bar{a}>$ knj. $\operatorname{sln} . \bar{a}$ (rez. sln. test, te $\neq$ knj. sln. tâst, tâ), v rezijanskem narečju pa se je ta $e$ v položaju ob $m$ in $n$ zožil v $i$ (rez. $\ln$. $d i n, m i h \neq \mathrm{knj}$. sln. dân, $m a ̂ h$, rez. sln. pet okin ,pet oken”). Severna slovenščina in zahodni del vzhodne slovenščine poznata pozno daljšanje slovenskih kratkih akutiranih zložnikov v predzadnjem zlogu in posledično dva različna odraza slovenskega *̌̌ v dolgih oz. podaljšanih zlogih: sln. *ē : *è̀- $>*_{i e}: * \bar{e}>$ rez. $i$ : ẹ (rez. lëtu : NApl lita = knj. sln. lẹ́to : NApl lệta; rez. jë jidal : jë jëdla = knj. sln. je jệdəl : je jệdla; rez. sln. dëlat : 2 sg praes. dilaš = knj. sln. dẹlati : 2 sg praes. dệlaš; rez. sln. dëd, Gsg dëda : didac = knj. sln. dëd, Gsg dẹda : dệdəc). $\mathrm{V}$ večini severnih slovenskih govorov je slovenski $* \bar{e}$ (najverjetneje v času okrog splošnoslovenske diftongizacije) sovpadel s slovenskim *ě̃: sln. *ě $=*_{\bar{e}}>\mathrm{S} \operatorname{sln} . *_{i e}>$ rez. $\operatorname{sln} . i \neq \operatorname{sln} . * \bar{e}: * \bar{e}>\mathrm{J} \operatorname{sln} . *_{e i}: *_{\bar{e}}>\mathrm{knj} . \mathrm{sln} . \bar{e}$ (rez. $\operatorname{sln}$. lis $=l i d \neq$ knj. sln. lệs = lệd). Podobno sta v večjem delu severne

${ }^{8}$ Kjer na to ni posebej opozorjeno, so navedene oblike standardne rezijanščine, zapisane v veljavnem rezijanskem pravopisu (Steenwijk 1994; 1999; 2005). 
slovenščine po denazalizaciji nosnih samoglasnikov slovenska $* \bar{e} / *$ è- sovpadla $\mathrm{z} * \bar{\partial} / * \dot{\partial}-: \operatorname{sln} . * \bar{\partial} / * \dot{\partial}-=* \bar{e} / * \dot{e}->\mathrm{S} \operatorname{sln} . * \bar{e}($ rez. $\operatorname{sln}$. test, tešća $=$ pet, gledat $\neq$ knj. sln. tâst, tášč $a$ : pệt, glẹ́dati).

Kot vsa ostala slovenska narečja je tudi rezijansko prizadela vokalna redukcija (naglašenih in nenaglašenih) kratkih samoglasnikov, ki pa v knjižno slovenščino ni bila sprejeta. Sem spada na primer znižanje kratkih naglašenih vogalnih samoglasnikov (rez. sln. meš, set = knj. sln. mïš, sït;

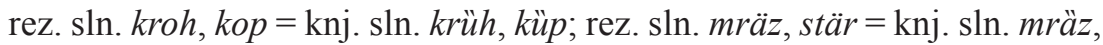
stär). Različna intenziteta vokalne redukcije je hkrati tudi vzrok za nastanek nekaterih razlik med posameznimi rezijanskimi krajevnimi govori; v zahodnih govorih Bile in Njive se pojavljata ikanje oz. ukanje, medtem ko prihaja v vzhodnih govorih Osojan in Solbice do akanja ali pa je stanje slovenskih ejevskih oz. ojevskih samoglasnikov nespremenjeno: Bila, Njiva bisída, nistèt, pitilèn, Osojane, Solbica basida, nastèt, patalèn, knj. sln. besệda, nestï > nésti, petelìn > petélin; Bila, Njiva klubük, kubila, mutïka, Osojane, Solbica klabük, kobila, motïka, knj. sln. klobúk, kobila, motîka.

$\mathrm{Z}$ ozemlja primorskih slovenskih narečij so se $\mathrm{v}$ rezijanščino širile mlajše glasovne spremembe. Od vzhoda proti zahodu rezijanščine se je širila spirantizacija prvotnega $* g$, ki pa skrajnega zahoda doline (govor vasi Bila) ni dosegla: sln. $*_{g}>*_{\gamma}>*_{h}>*_{x}>*_{\varnothing}\left(\right.$ sln. $*_{n o g a}>$ Bila $n \ddot{g} g a$,

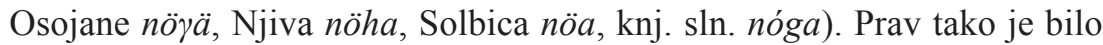
s prehodom sln. $* l>* u$, , ki je značilen samo za govor kraja Osojane (Osojane so imele preko svojih planin na Koritu in v Učji največ stika z govorci obsoškega in terskega narečja), medtem ko se je v ostalih rezijanskih govorih sln. * $t$ spremenil v srednji $l$ ( $\sin$. ${ }^{*}$ stot $>$ Solbica, Njiva, Bila stöl, Osojane stöw, knj. sln. stol [stoun]; sln. ${ }^{*}$ słza $>*_{\text {satza }}>*_{\text {sotza }}>$ Solbica solza, Njiva, Bila sulza, Osojane suza, knj. sln. solza [souzza] $)^{9}$.

Zelo značilni za rezijanščino so t. i. ,zasopli” samoglasniki (nem. lufterfüllte Vokale, kot jih je poimenoval Jan Baudouin de Courtenay): sln.

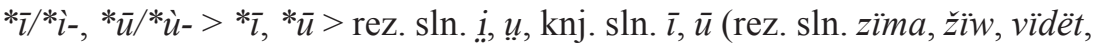
knj. sln. zíma, žîv, vídeti; rez. sln. düša, süh, Gsg krüha, knj. sln. dúša, sûh, Gsg krúha); sln. *è//*è > rez. sln. ẹ (sln. se žënin, cësta, lëtu, dëd, Gsg

${ }^{9}$ Trditev, da je rezijaščina jezikovni otok oz. knjižni/standardni mikrojezik jezikovnega otoka (rus. островной литературный микроязык), ki se pojavlja v Duličenkovih delih o slovanskih knjižnih/standardnih mikrojezikih (Duličenko 2003: 3; 2013: 27), torej ne drži. 
dëda, knj. sln. se žẹ́nim, cẹ́sta, lệto, dëd, Gsg dẹeda); sln. *ò >ọ (rez. sln. nösin, wöja, könj, knj. sln. nọ́sim, vọ́lja, könj). Gre za visoke in sredinske samoglasnike, ki so v primerjavi z „nezasoplimi” $i, u, e, o$ fonetično centralizirani.

Kot je bilo že nakazano, rezijansko narečje jezikovno ni enotno. Razlike so predvsem na glasovni ravnini, manj na oblikovni, v zelo omejeni meri pa tudi v besedju. V dolini srečujemo štiri glavne krajevne govore od zahoda proti vzhodu se zvrstijo govori vasi Bila (it. San Giorgio), Njiva (it. Gniva), Osojane (it. Oseacco) in Solbica (it. Stolvizza) - in vsaj tri podgovore: govore zaselka Lipovec (it. Lipovaz), ki je podsistem govora Njive, ter vasi Korito (it. Coritis) in Učjá (it. Uccea), ki sta podsistema govora Osojan.

\section{Rezijanščina sociolingvistično}

Rezijanščina je sociolingvistično opredeljena kot slovenski knjižni/ standardni mikrojezik (v slovenistiki je bolj uveljavljen termin pokrajinski ali krajevni knjižni jezik), ki na lokalni ravni zaradi odsotnosti „krovnega" slovenskega knjižnega/standardnega jezika opravlja vlogo knjižnega jezika z zelo omejenim naborom funkcijskih zvrsti. Predstavljena sta sociolingvistični položaj rezijanskega narečja in način oblikovanja knjižne/ standardne rezijanščine.

\subsection{Diglosija znotraj bilingvizma}

Za Rezijo (podobno velja deloma tudi za slovensko Benečijo, tj. Nadiške in Terske doline, Videmsko pokrajino v Italiji ter slovensko Porabje (madž. Rábavidék) na Madžarskem) je značilna - gledano sociolingvistično - odsotnost oziroma omejena prisotnost slovenskega knjižnega/standardnega jezika v javni rabi, za govorce slovenščine pa v večini primerov stanje diglosije/dvojezičja znotraj bilingvizma/dvojezičnosti, tj. model „,narečna zvrst materinščine - knjižna/standardna zvrst večinskega državnega jezika": slovensko narečje kot nizki register v zasebnem govornem položaju in italijanski knjižni jezik kot visoki register v javnem govornem 
položaju. Zaradi odsotnosti oziroma pomanjkljive prisotnosti slovenskega knjižnega/standardnega jezika (ter posledično tudi njegove narodnozdruževalne in narodnopredstavniške vloge) govorci slovenščine na imenovanem obrobju niso mogli v popolni meri izoblikovati zavesti o pripadnosti neki nadpokrajinski, tj. vseslovenski jezikovni skupnosti. Z obvladovanjem večinoma samo svojega narečja ostajajo zato na stopnji zavesti ozke slovenske pokrajinske pripadnosti, značilne za osrednjeslovenski prostor $\mathrm{v}$ času pred 19. stoletjem, ki se ji pridružuje državljanska zavest italijanske države. To stanje je posledica zgodovinske izkušnje teh ozemelj, pa tudi nezadostne dejanske jezikovne zaščitenosti.

Za dolino Rezije (kot tudi za slovensko Benečijo in Prekmurje s Porabjem) je bila skozi zgodovino predvsem zaradi lege na obrobju slovenskega jezikovnega prostora značilna političnoupravna ločenost od slednjega z državno mejo (Rezija in Benečija do leta 1420 pod Oglejskim patriarhatom, od 1420 do 1797 pod Beneško republiko, nato razen kratke Napoleonove dobe v Avstriji, od 1866 pod Italijo; Prekmurje s Porabjem v okviru madžarske države). Posledično ta ozemlja niso aktivno sodelovala pri kulturnih procesih, ki so bili v teku na osrednjem Slovenskem - od leta 1500 do 1918 v okviru habsburške monarhije (vojvodine Kranjska, Koroška in Štajerska, grofija Goriška in mesto Trst). Za osrednjeslovenski prostor je pomembna zlasti druga polovica 19. stoletja, ko po knjižnojezikovni neenotnosti 18. stoletja (kranjski knjižni jezik in koroška knjižna različica, prekmurski knjižni jezik in vzhodnoštajerska knjižna različica) nastane enoten slovenski knjižni jezik kot osnova za oblikovanje enotne slovenske jezikovne kulture in identitete; ta jezik se od leta 1848 ob nemščini postopoma uveljavlja kot uradni jezik znotraj tedanje Avstrije.

Opisano stanje danes ni le posledica zgodovinske izkušnje. Države, ki jim opazovana ozemlja upravnopolitično pripadajo, namreč niso v zadostni meri poskrbele za dejansko zaščito in razvoj avtohtonega slovenskega prebivalstva. Nasprotno, le-to je (bilo) podvrženo prikriti, če ne že kar odkriti asimilacijski politiki (Giornale di Udine je 22.11.1866 zapisal: Questi slavi bisogna eliminarli! [Te Slovane je potrebno odstraniti!]), ki je svoj vrhunec dosegla v času nacifašizma (1922-1943) in se de facto nadaljevala v obdobju po drugi svetovni vojni. Tako je zgodovinsko gledano sicer kompaktno poseljeno slovensko prebivalstvo danes na svojem - pred nekaj desetletji še homogenem - poselitvenem prostoru „manjšinizirano”. 
Govorci slovenščine v Videmski pokrajini za italijansko državo, v okviru katere živijo od leta 1866 (Nadiške in Terske doline, Rezija) oziroma 1918 (Kanalska dolina), do nedavnega tako rekoč niso obstajali in jezikovno niso bili zaščiteni. Kot del slovenske jezikovne skupnosti v Italiji (in s tem enakopravni govorcem slovenščine v Tržaški in Goriški pokrajini) so bili priznani šele z državnim zakonom št. 482 iz leta 1999, naslovljenim Predpisi o varstvu zgodovinskih jezikovnih manjšin. Slovenski jezik in njegove zemljepisne različice (narečja) so bili zaščiteni z državnim zakonom št. 38 iz leta 2001 (Zakonska določila za zaščito slovenske jezikovne manjšine $v$ deželi Furlaniji - Julijski krajini) ter z deželnim zakonom št. 26 iz leta 2007 (Deželna določila za zaščito slovenske jezikovne manjšine). Slednji eksplicitno določa, da zakonska določila veljajo tudi za rezijanščino ter slovenske jezikovne različice v Nadiških in Terskih dolinah ter v Kanalski dolini ${ }^{10}$. Omenjeni zaščitni zakoni pa se povsod v Videmski pokrajini dejansko ne izvajajo. Na področju javnega šolstva na primer z izjemo ene same dvojezične osnovne šole (5 let) in nižje srednje šole (3 leta) v kraju Špeter (it. San Pietro al Natisone) v Nadiških dolinah, ki je leta 1984 nastala kot zasebna šola in je bila s sprejetjem zakona št. 38/2001 podržavljena, slovenščina $\mathrm{v}$ Terskih dolinah, Reziji in Kanalski dolini od države ni sistematično financirana ne kot učni predmet ne kot učni jezik, niti v knjižni niti v narečni različici.

\subsection{Oblikovanje rezijanskega knjižnega/standardnega mikrojezika}

Zaradi skoraj popolne odsotnosti slovenskega knjižnega jezika v javnosti, pomembnosti narečja kot edinega nosilca jezikovne in kulturne identitete Rezijanov in zaradi v zgodovini že obstoječega rezijanskega

${ }^{10}$ Italijanska zakonodaja uporablja izraz jezikovna manjšina (it. minoranza linguistica), ne pa izrazov narodna, narodnostna, etnična manjšina, ter poleg knjižne/standardne slovenščine ščiti tudi zemljepisne jezikovne različice, tj. slovenska narečja v Videmski pokrajini (rezijansko, nadiško, tersko in ziljsko narečje v Kanalski dolini). Subjekt zaščite je torej slovenski jezik in ne slovenska narodnostna skupnost, iz česar sledi, da za aplikacijo zakona na nekem območju ni potrebno, da se njeni prebivalci identificirajo s slovensko narodnostno skupnostjo, temveč da želijo v javnosti uporabljati eno od različic slovenščine, knjižno/standardno ali narečno. 
knjižnega izročila ${ }^{11}$ je pri Rezijanih zrasla potreba po oblikovanju lastnega, pokrajinsko oziroma krajevno omejenega knjižnega jezika. V ta namen je rezijanska občinska uprava avgusta 1980 in decembra 1991 organizirala znanstveni srečanji na temo kodifikacije knjižne rezijanščine ${ }^{12}$ ter delo nato poverila nizozemskemu jezikoslovcu Hanu Steenwijku. V naslednjih desetletjih so izpod njegovega peresa izšli pomembni kodifikacijski priročniki, in sicer leta 1994 pravopis, leta 1999 prvi del slovnice ter leta 2005 mali pravopisni slovar (Steenwijk 1994, 1999, 2005).

Glavna problema standardizacije rezijanščine sta bila izbira črkopisa in premagovanje razlik med posameznimi krajevnimi govori. Kodifikator se je odločil za ,slovenski” način zapisovanja soglasnikov, tudi za pisanje sičnikov s, z, c (knj. rez. rösa, mïza, lisïca, knj. sln. rósa, míza, lisíca), ki pa se spričo rezijanskega nepoznavanja slovenskega knjižnega/standardnega jezika in navajenosti uporabnikov na italijanski pravopis lahko izbirno zapisujejo tudi na ,italijanski” način (knj. rez. rössa, mïsa, lissïza). Glavni štirje rezijanski krajevni govori (vasi Bila, Njiva, Osojane in Solbica) se med seboj ločijo predvsem na glasovni in oblikovni ravni, kjer so razlike v naboru končnic razložljive deloma z glasovnimi spremembami in deloma $\mathrm{z}$ različnimi izhodišči le-teh, manj pa $\mathrm{v}$ besedju. Na glasovni ravni obstajajo med njimi - gledano sinhrono - sistematične glasovne vzporednice, diahrono razložljive z različnimi odrazi. 28 je samoglasniških in 7 soglasniških, v knjižni jezik pa so bile sprejete značilnosti, prisotne vsaj v treh od glavnih štirih krajevnih govorov (Bila krüh, küp, Njiva kroh, kop, Osojani kroh, $k o p$, Solbica kro, kop $\rightarrow$ knj. rez. kroh, kop, knj. sln. krüh, küp). Če pojav ni prisoten vsaj v treh govorih, je v presojo pritegnjen govor zaselka Lipovec, ki ima med krajevnimi govori središčno lego (Bila myš, syt, Lipovec meš, set, Njiva meš, set, Osojane meř, set, Solbica myš, syt $\rightarrow$ knj. rez. meř, set, knj. sln. mï̌s, sït). Na glasovni in oblikovni ravnini jezikovnega sistema je Steenwijkova knjižna/standardna rezijanščina torej abstrakcija štirih glavnih krajevnih govorov in tako predstavlja odličen primer standardizacije knjižnega/standardnega jezika s pomočjo abstrakcije konkretnih organskih idiomov na osnovi spoznanj teoretičnega jezikoslovja.

\footnotetext{
${ }^{11}$ Starejše rezijansko knjižno izročilo je predstavljeno v Steenwijk 2003a.

${ }^{12}$ Razprave zadnje konference so zbrane v zborniku Fondamenti per una grammatica pratica resiana (Steenwijk 1993).
} 
Standardna rezijanščina se v pisni obliki pojavlja predvsem v publikacijah za šolsko populacijo, v člankih, objavljenih v lokalnem laičnem in verskem tisku ${ }^{13}, \mathrm{v}$ radijski oddaj ${ }^{14}$, zapisih ljudskih in avtorskih besednoumetnostih besedil ${ }^{15}$, priložnostno pri cerkvenih obredih ter občasno tudi na javnih dopisih in oglasih. Steenwijkovo standardno rezijanščino v svojih publikacijah uporabljajo kulturna društva Circolo Culturale Resiano Rozajanski dum, Associazione Culturale Museo della Gente della Val Resia, Coro Rože Májave in Gruppo Folkloristico Val Resia. Zakonska podlaga za pojavljanje rezijanščine v javnosti so zaščitni zakoni za slovensko jezikovno manjšino v Italiji. Kljub prisotnosti na različnih področjih javnega življenja pa je knjižna rezijanščina funkcijskozvrstno precej omejena. Razlog za to je predvsem omejenost narečnega leksikalnega fonda, s pomočjo katerega je zelo težko ubesedovati zahtevnejše vsebine. Na sodobno zunajjezikovno stvarnost vezano besedje se ob omejenosti lastnih tvornih besedotvornih postopkov tako praviloma prevzema iz večinskega državnega jezika - italijanščine, nikakor pa ne iz Rezijanom tujega slovenskega knjižnega/standardnega jezika. V Reziji opravlja torej rezijanski knjižni/standardni mikrojezik vlogo sporazumevalnega sredstva znotraj lokalne jezikovne skupnosti brez ambicij približevanja slovenskemu knjižnojezikovnemu izročilu.

Steenwijkova standardna rezijanščina, predvsem odločitev za ,slovenski” pravopis, pa v lokalni jezikovni skupnosti ni splošno sprejeta. Poleg njegovega sistemskega, znanstvenega, obstaja namreč tudi nesistemski pravopis, katerega avtor je Sergio Chinese (Chinese 2003). Potem ko je bil Chinese leta 2009 na lokalnih volitvah izvoljen za župana Rezije, je začela rezijanska občinska uprava njegov pravopis, uradno objavljen v občinskem glasilu Il Giornale di Resia (december 2009, str. 3), uveljavljati

${ }^{13}$ Rezijanski članki se v omejeni obliki pojavljajo v publicistiki ob italijanščini. Rezijansko kulturno društvo Rozajanski dum izda vsako leto tematski koledar Näš kolindrin z besedili v rezijanščini in italijanščini ter od leta 2006 dvakrat letno, občasno tudi trikrat, časopis „Näš glas - La nostra voce”. Rezijanska besedila se pojavljajo predvsem v periodičnih publikacijah Slovencev Videmske pokrajine, in sicer v tedniku „Novi Matajur” in polmesečniku „Dom”.

${ }^{14} \mathrm{~V}$ okviru Radia Trst A, slovenskega programa Deželnega sedeža RAI za Furlanijo - Julijsko krajino, pripravljajo Rezijani v rezijanščini polurno tedensko radijsko oddajo Te rozajanski glas.

${ }^{15} \mathrm{~V}$ rezijanščini ustvarjajo tudi nekateri pesniki (Renato Quaglia, Silvana Paletti) in kantavtor (Rino Chinese). 

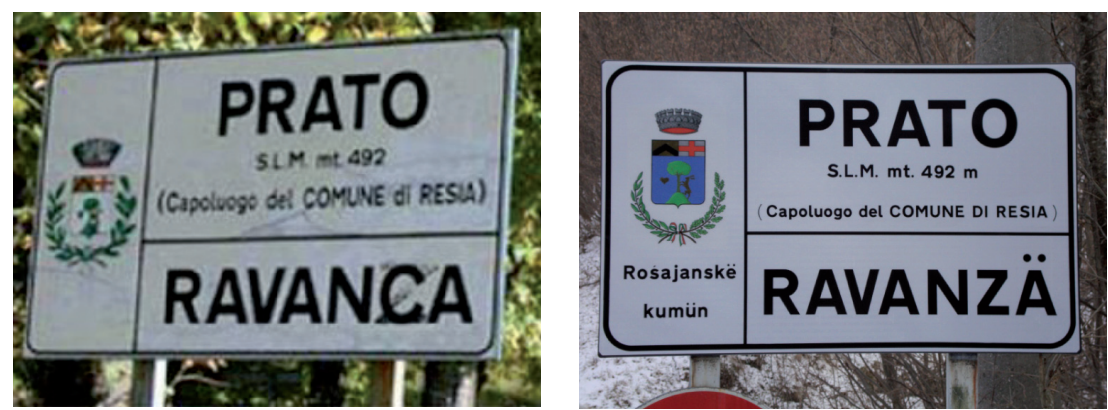

Al prav se piše Ravanca ali Ravanza?

v javnih napisih (krajevni napisi, smerokazi ipd.). Največja novost Chinesejevega pravopisa je zapisovanje glasu [z] z grafemom $<\dot{\text { ś }}>$ in glasu [c] na „,italijanski” način z grafemom < $<>$ (rösä, myśä, lysyzä). Publikacije zgoraj imenovanih kulturnih društev ostajajo še naprej v Steenwijkovem pravopisu $^{16}$. Rezijanski pravopisni spor nekoliko spominja na črkarsko pravdo v osrednjeslovenskem prostoru v obdobju 1824-1843, ki ji je pesnik France Prešeren leta 1832 namenil satirični sonet Al prav se piše kama ali kafha.

\section{Literatura}

Brozović D., 1960, O strukturalnim i genetskim kriterijima u klasifikaciji hrvatskosrpskih dijalekata, „Zbornik za filologiju i lingvistiku” št. 3, s. 68-88.

Brozović D., 1970, Standardni jezik. Teorija, usporedbe, geneza, povijest, suvremena zbilja, Zagreb.

Brozović D., 1996, Sociolingvistika prema genetskoj i tipološkoj lingvistici, „Suvremena lingvistika" št. 41-42(1-2), s. 87-94.

Chinese S.H., 2003, Rośajanskë-laškë bysidnjäk. Repertorio lessicale italiano-resiano, Resia.

${ }^{16}$ Han Steenwijk je leta 2003 izid Chinesejevega slovarja pozdravil z navdušenjem (,E finalmente il lettore tiene in mano un dizionario resiano! (...) Una circostanza per noi particolarmente piacevole risulta il fatto che l'autore cui va il merito per questa impresa è Sergio Chinese di Lipovaz" - Steenwijk 2003: 7), medtem ko je uvedbo Chinesejevega pravopisa kot uradnega za rezijansko občino leta 2010 ostro kritiziral („In poche parole, partendo da premesse sbiagliate si è presa una decisione sbagliata che sta per essere implementata in modo sbagliato" - Steenwijk 2010: 9). 
Comrie B., Corbett G.G. (ur.), 2002, The Slavonic Languages, London-New York.

Dapit R., 1995, 1998, 2008, Aspetti di cultura resiana nei nomi di luogo 1-3, Padova.

Dapit R., 2003, Nastajanje krajevnih knjižnih jezikov pri Slovencih v Furlaniji, v: Knjižni jezik-aktualna vprašanja in zgodovinske izkušnje (Obdobja 20), ur. A. Vidovič Muha, Ljubljana, s. 301-312.

Dapit R., 2006, The Resian dialect and its evolution as a literary language, v: Славянскые литературные микроязыки и языковые контакты, ur. A.D. Duličenko, S. Gustavsson, J. Dann, Tartu, s. 166-175.

Duličenko A.D., 1994, Kleinschriftsprachen in der slavischen Sprachenwelt, „Zeitschrift für Slawistik" št. 39, s. 560-567.

Havránek B., 1963a, Funkce spisovného jazyka, v: B. Havránek, Studie o spisovném jazyce, Praha, s. 11-18.

Havránek B., 1963b, Úkoly spisovného jazyka a jeho kultura, v: B. Havránek, Studie o spisovném jazyce, Praha, s. 30-59.

Havránek B., 1969, Teorija knjižnega jezika, „Jezik in slovstvo” št. 14(7), Ljubljana, s. 196-204.

Okuka M. (ur.), 2002, Wieser Enzyklopädie des europäischen Ostens 10: Lexikon der Sprachen des europäischen Ostens, Klagenfurt/Celovec-Wien-Ljubljana.

Rehder P., 1995, Standardsprache: Versuch eines dreistufigen Modells, „Die Welt der Slawen" št. 40, s. 352-366.

Rehder P. (ur.), 1998, Einführung in die slavischen Sprachen: mit einer Einführung in die Balkanphilologie, Darmstadt.

Steenwijk H., 1992, The Slovene dialect of Resia: San Giorgio, Amsterdam.

Steenwijk H. (ur.), 1993, Fondamenti per una grammatica pratica resiana: Atti della conferenza internazionale tenutasi a Prato di Resia (UD) 11-12-13 dicembre 1991, Padova.

Steenwijk H., 1994, Ortografia resiana/Tö jošt rozajanskë pïsanjë, Padova.

Steenwijk H., 1997, Tre studi resiani: Grammatica e storia sociale, Padova.

Steenwijk H., 1999, Grammatica pratica resiana: Il sostanitvo, Padova.

Steenwijk H., 2003a, The roots of written Resian, v: Knjižni jezik-aktualna vprašanja in zgodovinske izkušnje (Obdobja 20), ur. A. Vidovič Muha, Ljubljana, s. 313-322.

Steenwijk H., 2003b, Dizionari resiani, v: S.H. Chinese, Rośajanskë-laškë bysidnjäk. Repertorio lessicale italiano-resiano, Resia, s. 7-14.

Steenwijk H., 2005, Piccolo dizionario ortografuico resiano. Mali bisidnik za tö jošt rozajanskë pïsanjë, Padova.

Steenwijk H., 2010, L'adozione di una grafia ,ufficiale” del Comune di Resia e le sue conseguenze, „Näš glas - La nostra voce” št. 6(1), 2010, s. 1-9.

Šekli M., 2001, Rezja, Rezjanie i dialekt rezjański, „Zeszyty Łużyckie” št. 32-33, s. $49-57$.

Šekli M., 2003, Jezik, knjižni jezik, pokrajinski oz. krajevni knjižni jezik: genetskojezikoslovni in družbenostnojezikoslovni pristop $k$ členjenju jezikovne stvarnosti (na primeru slovenščine), v: Aktualizacija jezikovnozvrstne teorije na Slovenskem: členitev jezikovne resničnosti (Obdobja 22), ur. E. Kržišnik, Ljubljana, s. 41-58. 
Šekli M., 2006a, Praslovanski stari cirkumfleks v rezijanskem in ziljskem narečju slovenščine, v: Diahronija in sinhronija v dialektoloških raziskavah, ur. M. Koletnik, V. Smole, Maribor, s. 227-287.

Šekli M., 2006b, Pokrajinski/krajevni knjižni jeziki na Slovenskem, v: XXXII научна конференција XXXVIII на меѓнароден семинар за македонски јазик, литература и култура (Охрид, 15. VIII - 17. VIII 2005), ur. Е. Црвенковска, Скопје, s. 195-206.

Šekli M., 2007, Narečjeslovje in zgodovinska slovnica kot pomoč pri razumevanju pravopisa in pravorečja (na primeru zasoplih samoglasnikov v rezijanskem krajevnem knjižnem jeziku), v: Živeti mejo (Zbornik Slavističnega društva Slovenije 18), ur. M. Košuta, Trst, s. 181-192.

Šekli M., 2009, Merila določanja mej med slovenskimi narečji in podnarečji, v: Slovenska narečja med sistemom in rabo (Obdobja 26), ur. V. Smole, Ljubljana, s. 291-318.

Šekli M., 2013a, Genetolingvistična klasifikacija južnoslovanskih jezikov, „Jezikoslovni zapiski” št. 19(1), s. 71-99.

Šekli M., 2013b, Genetic classification of West Slavic languages, v: Miklošičeva monografija: ob dvestoletnici rojstva Franca Miklošiča, ur. M. Jesenšek, Ljutomer, s. $101-115$.

Šekli M., 2014a, Genetolingvistična klasifikacija vzhodnoslovanskih jezikov, „Slavia Centralis" št. 7(1), s. 5-20.

Šekli M., 2014b, Tipologija modelov lingvogeneze slovanskih jezikov, „Slavistična revija” št. 62(2), s. 451-461.

Valentinčič D., 2014, Slovenci v Reziji? Pravni položaj in dejansko življenje slovenske jezikovne manjšine, Celovec/Klagenfurt - Ljubljana - Novo mesto.

Дуличенко А.Д., 1981, Славянскые литературные микроязыки: вопросы формирования и развития, Таллин.

Дуличенко А.Д., 1998, Языки мальх этнических групп: статус, развитие, проблемы выживания, v: Языки малье и большие: in meтoriam acad. Nikita I. Tolstoi, ur. А.Д. Дуличенко, Tartu, s. 26-36.

Дуличенко А.Д., 2002, Литературные микроязыки современной Славии: проблемы кодификации и языковая практика, v: Möglichkeiten und Grenzen der Standardisirung slavischer Schriftsprachen in der Gegenwart, ur. K. Gutschmidt, Thelem, s. 14-32.

Дуличенко А.Д., 2003, Славянскые литературные микроязыки: образцы текспов, Tartu.

Дуличенко А.Д., 2006, Современное славянское языкознание и славянские литературные микроязыки, v: Славянскые литературные микроязыки и языковые контактыл, ur. A.D Duličenko, S. Gustavsson, J. Dann, Tartu, s. 22-46.

Дуличенко А.Д., 2013, Феномен славянских микрофилологий в современном славяноведении, v: Славистика в Естонии и за ее пределами, ur. А.Д. Дуличенко, Tartu, s. 17-30. 
